\title{
Nanomechanical characterization of porous anodic aluminum oxide films by nanoindentation
}

\author{
Zhong $\mathrm{Hu}^{*}{ }^{* 1}$, Maheshwar Shrestha ${ }^{2}$, Qi Hua Fan ${ }^{* 2}$ \\ ${ }^{1}$ Department of Mechanical Engineering, South Dakota State University, Brookings, SD, USA \\ ${ }^{2}$ Department of Electrical Engineering \& Computer Science, South Dakota State University, Brookings, SD, USA
}

\begin{abstract}
Nanostructured thin films have gained great interests in recent years due to their significantly enhanced properties and great potential for various applications. Nanoindentation techniques are commonly used to measure nanomechanical properties of thin films and the surface layers of bulk materials. In this article, nanoindentation tests coupled with computer modeling were proposed to characterize nanostructured porous anodic aluminum oxide (AAO) films grown on glass. A three-dimensional nanoindentation model was developed. The Young's modulus and hardness were measured by nanoindentation using a Berkowich pyramidal sharp tip indenter. The effects of the substrate and porous structure of the film on the coating measurements were investigated. The dilemma for extracting the mechanical properties of a porous structural film in nanoindentation has been pointed out, and an alternative approach of combined modeling/experimental provided a justification by considering the porous structure of the film and minimizing the influence of the substrate. Computer modeling results were validated by experimental data.
\end{abstract}

Keywords: Glass substrate; Nanostructured porous coating; Anodic aluminum oxide; Nanoindentation; Finite element analysis.

* Corresponding authors: Email address: zhong.hu@sdstate.edu, and qihua.fan@sdstate.edu. 


\section{Introduction}

Nanostructured materials, thin films, and coatings offer the potential for significant improvements in physical properties, such as optical, electromagnetic, thermal, and mechanical properties. Nanoscale characterization is a critical step to understanding the properties of nanostructured materials that possess microstructural features about 100 to 1000 times smaller than conventional engineering materials. Surface morphology can be characterized using techniques such as scanning probe microscopy (SPM) (e.g., atomic force microscopy) and scanning electron microscopy (SEM). Thin-film cross section can be analyzed using transmission electron microscopy (TEM), SEM, X-ray and neutron scattering [1]. Direct measurement of the mechanical properties of thin films and nanostructured materials is particularly challenging, because traditional mechanical tests are not suitable in most cases. Scaling down the conventional mechanical tests has led to novel techniques that have enriched knowledge in nanomaterial properties, such as Young's modulus, hardness, yield strength, strainrate sensitivity, strain-hardening rate, friction and wear resistance, and fracture strength [2]. Among these nanoscale-mechanical-characterization techniques, nanoindentation is particularly attractive.

Nanoindentation measurement is based on continuously monitoring the load and the depth of an indenter during an indentation process at the micro-/nano-scale. This technique has been significantly improved over the past 30 years and has become popular for assessing mechanical response at high spatial resolution. One of the advanced applications of nanoindentation is to determine the mechanical properties of thin films and coatings. In nanoindentation tests, the properties of a thin film may be measured without removing the film from the substrate as needed in other types of tests. By continuously recording the load and indenter displacement, a single test produces a load-depth curve that can be further analyzed to determine the mechanical 
properties of the material [3-59].

The main difficulty encountered in nanoindentation of thin films and coatings is to avoid probing the properties of the substrate and to separate the influence of the substrate from the measurement data. To achieve this, it is common to restrict the maximum depth of penetration in a test to no more than $10 \%$ of the film thickness, although research suggests that this rule has no physical basis $[46,54,58]$. On the other hand, controlling indentation penetration within $10 \%$ of the film thickness requires very small load and leads to great errors in the test data. A number of researchers have attempted to derive expressions that correlate measured thin film properties with substrate properties and composite properties (measured on coated substrate). The proposed models are based on the theoretical analysis or numerical simulation, taking into account a number of factors, such as the effects of the film thickness, the $P$ - $h$ behavior, the pile-up or indentation profile, and the indenter contact radius or pressure distributions $[3,5-7,11,15-18,20$ $23,25-32,34,36-38,40-42,44,45,48,49,52,53,59]$; the plastic zones in the film and substrate or laws of mixture of the area or volume fractions $[8,13,14,16-19,25,30,36,42,51]$; the response of the elastic and plastic deformation of both the film and substrate and the film-substrate composite associated with the indentation [4,6-11,23,24,26,32,41,45,52]; the various shapes/types of the indenters (such as cylindrical $[9,14,44]$, conical $[5,10,14,44,46]$, spherical $[3,8,15,17,22-24,28]$, Vickers $[9,29,37,43]$, and Berkovich $[6,9,23,30,37,41,43,45,48,59]$ indenters); the different film-substrate combinations for which the substrate is either harder or softer than the film $[8,11,16,35,36]$; the film and substrate having different yield strengths or Young's moduli or hardness $[10,11,47]$; the features regarding interface, structure, failure, time and energy, and porosity of the films [8,12,20,33,37,39,43,46,48,49,51,54,59]. The transitional functions represent the connection of the composite response of the film/substrate system to the individual responses of the film and the substrate and are sensitive to the mechanical properties 
of film and the substrate. Even with well controlled and systematic nanoindentation experiments, which can provide valuable insights on the material properties and help practical designs, accurate prediction of the material properties is impossible without parallel modeling effort. Therefore, finding a way to overcome the limitation of the minimum penetration and to separate the influence of the substrate from the measurement data is a key to successfully characterizing thin films and coatings by nanoindentation.

Amongst many important thin-film applications, antireflection coatings in solar panels are highly desired to obtain high energy-conversion efficiency. Common antireflection coatings on glass include multiple thin layers that need precise control of the film thickness and hence are expensive [60-64]. Porous anodic aluminum oxide (AAO), a mixture of air and alumina, has the potential to meet the requirements. By tuning the materials porosity, the effective refractive index of AAO film can be adjusted between that of air $(n=1)$ and alumina $(n=1.7)$. Hence porous AAO on glass $(n=1.54)$ can serve as low-cost antireflection coatings [65]. Therefore, research on the optical properties of AAO films grown on glass has been reported in recent years [66-68]. However, the porous nanostructure of AAO films grown on glass creates even bigger challenge than continuous thin films in interpreting nanoindentation test results. Hence, the fundamental mechanical properties of AAO films remain unclear.

In this article, aluminum thin films on glass were anodized and subsequently etched to create porous AAO films [65]. SEM and three-dimensional laser microscopy were used to determine the composition, microstructure, surface morphology and cross section of the porous AAO. Nanoindentation with a Berkowich pyramidal sharp tip indenter was adopted for the characterization of the nanostructured porous AAO films. The Young's modulus and hardness of the film were measured. Computer modeling based on FEA was conducted and a threedimensional nanoindentation model was developed. The influence of the substrate was identified. 
The film mechanical properties were extrapolated with the aid of computer modeling and validated by experiments.

\section{Experiment}

\subsection{AAO coating sample preparation}

The fabrication procedure of porous AAO nanostructures on glass [65] is shown in Figure 1. Aluminum thin film of $500 \mathrm{~nm}$ in thickness was deposited on glass slide $(7.6 \times 2.6 \times 0.1 \mathrm{~cm})$ by sputtering. The coated glass was cut into small pieces $(3.6 \times 1.3 \mathrm{~cm})$, which were ultrasonically cleaned in Ultrasonicator FS 60D (Fisher Scientific) using DI water, IPA and acetone for 10 minutes each before anodization. Then, the glass slide was electrochemically anodized to form porous $\mathrm{Al}_{2} \mathrm{O}_{3}$. As reported in previous studies, the anodic aluminum oxide grown at room temperature possesses amorphous structure [65,69-72]. After anodization, the samples were etched to increase the porosity. Surface morphology and cross section of the anodized samples were analyzed using Hitachi S-3400 N SEM and Keyence VK-9710 3D laser scanning microscope. Figure 2 shows the SEM images of the surface morphology and the cross section, and 3D laser microscope image of the porous profile of the resulting AAO film [65].

Statistical analysis of the measured data showed that the average diameter and depth of the pores were about $160 \mathrm{~nm}$ and $644 \mathrm{~nm}$, respectively, the average thickness of the AAO layer was about $744 \mathrm{~nm}$, and the average distance between the center points of two adjacent pores was about $270 \mathrm{~nm}$.

\subsection{Nanoindentation Test on AAO Coating}

Nanoindentation based on NANOVEA nanoindentation platform setup with a Berkovich pyramidal sharp-tip indenter was utilized to obtain load-depth curves. Since the test is in the nano-scale, the geometry and the quality on the very tip of the indenter are critical to the accuracy and reliability of the testing results. Figure 3 shows the SEM image of a Berkovich 
indenter tip used in the tests. It clearly shows the good quality of the sharp tip (smooth faces and clear edges of the tip area). The ideal angle between the vertical axis and any of the tip inclined faces is $65.27^{\circ}$, and the average measured value was $65.3^{\circ} \pm 0.3^{\circ}$. The three faces should be symmetrically placed around the vertical axis at $120^{\circ}$ apart, and the average measured value was $120^{\circ} \pm 1^{\circ}$. The SEM image of the Berkovich impression on the porous AAO thin film coated on the glass slide substrate is shown in Figure 4 which corresponds to the maximum indentation load of $40 \mathrm{mN}$. It clearly shows damage and cracks under the indent due to the brittleness of the alumina film and large deformation of the indent. It was also found that with small indentation load, it is hard to find the clear indent due to the high stiffness and elastic recovery of the film. The NANOVEA nanoindentation tester used independent force and depth sensors which were separately calibrated using equipment-traceable standard mass and length under continuous measurement of applied load during the indentation, providing high quality, accurate and repeatable results at the nanoscale. Using a mapping technique provided by the NANOVEA nanoindentation system, multiple indentations were performed. The parameters used in controlling the test included: approach speed of $1 \sim 3 \mu \mathrm{m} / \mathrm{min}$ (high speed for soft material, and low speed for hard material such as the glass substrate and the AAO thin films), contact load of $0.05 \mathrm{mN}$, maximum load of $5 \sim 80 \mathrm{mN}$, and corresponding load rate of $10 \sim 160 \mathrm{mN} / \mathrm{min}$. Indentation tests were done on the bare glass substrate (amorphous $\mathrm{SiO}_{2}$ ) and porous $\mathrm{AAO}$ formed on the glass slide. Figure 5 shows a typical indentation load vs. depth curve of the AAO coating recorded by the testing device.

The reduced Young's modulus $E_{r}$ of the specimen was obtained from the formulation in $[73,74]$. When the indentation depth approaches zero, $E_{r}$ represents the response from the AAO coating. Hence, the Young's modulus $E_{f}(=E)$ of the film can be obtained, where $E_{i}=1140 \mathrm{GPa}$ and $v_{i}=0.07$ are the Young's modulus and Poisson's ratio of the diamond indenter, respectively; $v$ 
is the Poisson's ratio of the coating. The average data obtained from the indentation tests under the same indentation load and the corresponding standard deviation for the measurements are listed in Table 1, in which each data under the same indentation load is the average value of 5 to 9 repeated tests. Due to the resolution limitation of the nanoindentation instrument, the minimum load for the indentation was about $5 \sim 10 \mathrm{mN}$, which resulted in relatively large penetration. Therefore, nanoindentation tests alone could not directly assess $h / t \rightarrow 0$, a necessary condition for extrapolating the coating properties. Therefore, computer modeling is needed.

\section{Nanoindentation Modeling}

Commercial FEA software ANSYS ${ }^{\circledR}$ was used to model the nanoindentation process [75]. A 3-D structural solid element type SOLID185 was adopted for modeling 3-D Berkovich indenter tip and specimen. The material properties were isotropic and elasto-plastic for glass substrate and the amorphous nano-porous AAO coating, and isotropic and elastic for the diamond indenter tip [76-80]. Young's moduli and Poisson's ratios of glass and alumina are 73.1 GPa, 0.17; and $370 \mathrm{GPa}, 0.21$, respectively. The stress-strain curve for uniaxial tensile deformation of amorphous silica (glass slide substrate) was taken from the experimental data [77] and converted to true-stress and true-strain curve for input. The deformation was primarily elastic at the beginning, companying with small plastic deformation. Larger plastic deformation started when the strain was great than 0.10 . Since the substrate (glass slide) was under the AAO coating, the deformation of the indentation testing for the thin film was primarily elastic deformation. The stress-strain curves (constitutive uniaxial elastic-plastic model) of the alumina was assumed for the calculations [76,78]:

$$
\sigma=E \varepsilon \quad\left(\sigma<\sigma_{y}\right), \quad \sigma=K \varepsilon^{n} \quad\left(\sigma \geq \sigma_{y}\right)
$$

where $\sigma_{y}$ is the yield strength, $n$ is the dimensionless strain-hardening coefficient with value between 0 (fully plastic) and 1 (fully elastic), and the $K$ parameter is set to 


$$
K=\left(\frac{E}{\sigma_{y}}\right)^{n} \sigma_{y}
$$

to guarantee the continuity of the function at $\sigma=\sigma_{y}$. The starting point of the yield strength is about $1.11 \mathrm{GPa}$, and the $0.1 \%$ offset yield strength is about $2.60 \mathrm{GPa}$. The parameter, $n$, was iteratively adjusted by trial and error to fit the indentation load-depth testing data using FEA modeling.

The elements have nonlinear capabilities, such as large strain, large deflection, and elasto-plastic stress-strain. To model the contact between the tip surface of the indenter and the sample testing surface, a surface-to-surface contact model was used, in which 3-D target segment TARGE170 representing various "target" surface and 3-D contact element CONTA173 representing associated contact surfaces were employed. Coulomb and shear stress friction were allowed. The modeled Young's modulus of the specimen was sensitive to the AAO thickness and the FEA model was much smaller than the real one due to the limitation of the total number of elements and computational time. These factors led to the introduction of a spring element COMBIN39 at the bottom of the model to correct this expected error caused by insufficient thickness of the AAO layer. COMBIN39 is a unidirectional element with nonlinear generalized force-deflection capability that can be used to treat real continuous materials as discretized element and to characterize the interactions between the material points in the area away from the plastic deformation zone. Thus, COMBIN39 defines elastic properties of the physical body. The element has longitudinal capability in three dimensional applications. The longitudinal option is a unidirectional tension-compression element with large displacement capability and up to three degrees of freedom at each node.

The three-dimensional meshed models for the glass slide only and for the porous AAO film on glass substrate are shown in Figure 6. The model dimensions were $30 \mu \mathrm{m}$ in diameter, $15 \mu \mathrm{m}$ 
in height for the glass substrate, and $0.744 \mu \mathrm{m}$ in thickness for the AAO film.

Since the deformation during the indentation process was primarily concentrated near the indenting area, fine mesh in the indenting area and the indenter tip was created to improve the modeling accuracy and save computing time. A symmetric plane was assumed for the indentation model. Hence, only halves of the specimen and indenter were generated for modeling. The proper element size, total elements, and total nodes were eventually determined through convergence study of the indentation load vs. depth; the models and corresponding mesh in Figure 6 serve as illustration only.

Defining proper boundary and loading conditions was the key for getting a reliable solution. Each node on the bottom of the solid model was linked with a spring element vertically aligned, and the other end of each spring element was constrained. The stiffness coefficients of the spring elements were determined by fitting Young's modulus of glass slide at the different indenting depths so that the model could be used to precisely simulate the nanoindentation testing for the coating/substrate system. All the nodes on the top of the indenter were constantly moving downwards for indentation test and then upwards for unloading. All the nodes on the symmetric plane $(x=0)$ were constrained without perpendicular displacements $\left(u_{x}=0\right)$. The friction coefficients between the diamond indenter tip and metallic materials was about 0.15 and was not sensitive to the change of the friction coefficient [81-86]. The modeling data are listed in Table 2.

\section{Results and Discussion}

The indentation modeling for glass slide was calibrated by adjusting the stiffness coefficients of the spring elements attached underneath the solid specimen to ensure that the Young's moduli from the modeling were consistent at different indentation depths $\left(E_{\text {glass }}=73.1\right.$ GPa), as shown in Table 2(a). It was found that the hardness of the glass was around 14 GPa by 
modeling. The modeled Young's moduli were consistent with experimental data, referring to Table 1(a) and Table 2(a), except that the modeling data of the hardness of the glass slide $(\sim 14$ $\mathrm{GPa})$ in Table 2(a) is greater than the experimental data ( 10 GPa) in Table 1(a). The reasons for such error were due to 1) the high plastic deformation during indentation on glass which reaches about $30 \%$ to $60 \%$ or even greater as indentation depth increased, 2) lacking of accurate description of large stress-strain deformation relationship of the glass under uniaxial tensile test, and 3) the data from molecular dynamics modeling [77] or assumed constitutive uniaxial elasticplastic model for the calculation [78] was approximated. However, the Young's modulus provided by the experiments from the references was accurate. Therefore, the modeling results on the Young's modulus were reliable.

The elastic deformation associated with an indentation extends to a much greater distance than the plastic deformation does. Therefore, generating data that is not influenced by neighboring phases is difficult. In many cases the best way to estimate the elastic modulus of a thin film is to make tests with a range of indentation sizes and extrapolate the results to about zero contact depth. For better accuracy, modeling the indentation response of the composite is required.

The hardness of a film and substrate combination is more difficult to quantify than the elastic modulus due to the complex nature of the plastic zone as it interacts with the substrate material, and the efforts for extracting the hardness values of thin films from the combination of film and substrate were reviewed in [58], and different empirical formulae were proposed $[4,7,8,12,19,25,29,33,35,36,39,40,46]$, in which parameters influencing the combined hardness of the film-substrate system were considered.

Despite these analytical and empirical treatments, no one relationship has been proposed to cover a wide range of materials behaviors. The analytical solution of the stress distribution in 
thin film and substrate systems by indentation loading has traditionally been very difficult; this information is usually obtained by FEA. Despite the fundamental difficulties in extracting the properties from the load-penetration depth data from the nanoindentation tests, it is a relatively straightforward procedure to undertake a series of tests or modeling with a conical or pyramidal indenter at differing depths and to plot the measured combined properties against the scaling parameter $h / t$. The coating properties can be therefore found by extrapolating the curve of the best fit to a data point of $h / t \rightarrow 0[41,58]$.

The indentation modeling data for porous AAO on glass substrate at different indentation depths are listed in Table 2(b). The comparison of the modeling with experiments on Young's moduli and the hardness of the porous AAO film on glass substrate at different indentation depths are plotted in Figure 7. It can be seen that the Young's modulus changes with the indentation depth. As the contact depth approaches a very small value $(h / t \rightarrow 0)$, the Young's modulus reflects the film property $\left(E \rightarrow E_{\mathrm{AAO}} \approx 370 \mathrm{GPa}\right)$ of the dense area, since the indentation test by modeling was conducted on the dense area among the pores. As the contact depth increases, the Young's modulus approaches a value slightly lower than the substrate, $E_{\text {Glass }} \approx 73.1$ GPa (Figure 7a), which is believed due to complex interactions between the porous AAO film and the glass substrate. Due to the stability and resolution of the tests, the minimum indentation depth was limited to no less than around $250 \mathrm{~nm}$, corresponding to a maximum indentation load of 5-10 mN. Therefore, nanoindentation tests couldn't give enough resolution for $h / t \rightarrow 0$ to directly reveal the thin film properties. On the other hand, the indentation modeling was able to extrapolate the film properties at much smaller indentation depth. In this case, the proposed function to fit the modeling and experimental data of Young's moduli is given by

$$
E=60+\left(E_{A A O}-60\right) \exp \left[-3.8\left(\frac{h}{t}\right)^{0.6}\right](\mathrm{GPa})
$$

which is also plotted in Figure 7(a). Equation (3) indicated that when the indentation gets 
infinitesimal, i.e., $h / t \rightarrow 0$, the Young's modulus approaches the film's property on the dense area, $E_{f}=370 \mathrm{GPa}$, and when the indentation depth gets deep enough, the Young's modulus approaches $60 \mathrm{GPa}$ which is slightly lower than to-the Young's modulus of the substrate, $E_{\text {glass }}=$ 73.1 GPa, due to the combination contributions of the elastic-plastic deformation from both the substrate and the porous AAO film. Figure 7(b) shows that the hardness of AAO film also changes with the indentation depth. As the contact depth approaches a very small value $(h / t \rightarrow 0)$, the hardness is expected to be the film property of the dense area $\left(H \rightarrow H_{\mathrm{AAO}} \approx 10.5 \pm 2 \mathrm{GPa}\right.$ for amorphous structure of this case [16,87], while for crystalline structure $H_{\mathrm{AAO}} \approx 24.7 \pm 2.5 \mathrm{GPa}$ to $28.9 \pm 2.3 \mathrm{GPa}[88])$. As the contact depth increases, the hardness approaches a much lower value (3-4 GPa), which is neither the hardness of the AAO layer nor that of the glass substrate. The large deviation of the hardness testing data reflects the complexity of the elastic-plastic deformation of the indentation for the porous AAO film, largely depending on where the nanoindentations are placed and how the porous structure (pores) of the film responses to the indentation. The proposed function to fit the modeling and experimental data of hardness is shown in Figure 7(b) and given by

$$
H=3+\left(H_{A A O}-3\right) \exp \left[-3.45\left(\frac{h}{t}\right)^{0.9}\right](\mathrm{GPa})
$$

Figure 8 illustrates the distribution of equivalent stress (von Mises stress) in the glass slide and $\mathrm{AAO} /$ substrate at different indentation depth. Under small indentation depth (e.g. $50 \mathrm{~nm})$, the stress distribution in the glass slide appeared like a hemi-spherical progressive field with a large maximum stress right underneath the indenter, as shown in Figure 8(a). In the case of $\mathrm{AAO} /$ substrate, the stress distribution was quite different. a larger spherical field distributed primarily in the AAO layer with a much smaller maximum stress in the center of the sphere, as shown in Figure 8(b). Note that under the small indentation depth, the effect of the glass substrate was negligible. The effect of the porous structure (pores) of the AAO film around the 
indentation, or in other words, the stress expanding to the surrounding area in the AAO film was limited. Under a larger indentation depth (e.g. $250 \mathrm{~nm}$ ), the stress distribution in the bare glass slide still kept a shape of roughly hemi-spherical progressive field with a much higher maximum stress underneath the indenter, as shown in Figure 8(c). However, in the AAO/substrate sample, the effect of the glass substrate was significant. The stress distribution in the glass substrate formed a hemi-spherical and progressive field with a maximum stress underneath the film, which was vertically aligned with the indenter pointer. The influence of the substrate can be also found from the indentation load-depth curve in Figure 5. At the beginning of the loading the depth increased rapidly until it reached $240 \mathrm{~nm}$ and then slightly slowed down. Furthermore, the effect of the pores in the AAO film around the indentation, or in other words, the stress expanding to the surrounding area in the AAO film was significant. In addition, the stress in the AAO layer was relatively uniformed and small underneath the indenter (even smaller than that in the substrate), as shown in Figure 8(d). This indicates that the stress was released due to the deformation nature of the porous AAO film.

On the other hand, the Young's modulus measured by nanoindentation depended strongly on the elastic deformation induced during the indentation loading and unloading processes, In the AAO porous structures, elastic deformation expanded deeply into the surrounding area, which made the experimental or modeling values of the Young's modulus much sensitive to the indentation depth. A deeper indentation led to a stronger influence from the surrounding porous AAO structures and the glass substrate on the elastic deformation distribution (see Figures 8 (b) and 6(d)). Consequently, the Young's modulus was more sensitive to the measurement conditions and became less reliable (see Figure 7 (a) and Table 2(b)).

Figure 9 shows the distribution of the total equivalent strain (von Mises strain) in the glass slide and AAO/substrate at different indentation depth. Under a small indentation depth (e.g. 50 
$\mathrm{nm})$, the strain distribution in both cases appeared like a hemi-spherical progressive field with a maximum strain underneath the indenter. The differences were that the hemi-spherical field was deeper and the maximum strain underneath the indenter was smaller in the bare glass slide than in the AAO/substrate sample, as shown in Figure 9(a) and (b). In the case of AAO/substrate, the effect of the porous structure of the AAO film around the indentation, or in other words, the strain expanding to the surrounding area in the AAO film was limited, as shown in Figure 9(b). Under a larger indentation depth (e.g. $250 \mathrm{~nm})$, the strain distribution in the glass slide still kept a hemi-spherical progressive field with a maximum strain underneath the indenter, as shown in Figure 9(c). In the case of AAO/substrate, the strain filed was similar to that in the glass slide sample with a larger distribution area and a larger plastic deformation. The effect of the porous structure of the AAO film around the indentation, or in other words, the strain expanding to the surrounding area in the AAO film was significant, as shown in Figure 9(d).

The information derived from Figures 8 and 9 well explains why the Young's modulus and hardness of the AAO/glass approach the values lower than that of either the substrate or the dense area of the AAO film when the indentation gets deeper; the effects of the substrate and the porous structure of the AAO film around the indentation play the critical role.

\section{Conclusions}

Using nanoindentation to evaluate the mechanical properties of a thin film grown on a substrate requires the contact depth to be very small. Due to the stability and resolution limitation of the nanoindentation test, the minimum indentation depth is still too large and nanoindentation could not directly access the film properties. Therefore, computer modeling is needed.

This study shows that nanoindentation test coupled with computer modeling is an

effective means for characterizing the mechanical properties of nanostructured thin films. A 
proper 3D FEA model is crucial to the successful simulation and calibration of the indentation tests. The computer modeling is validated by corresponding experimental data.

The complexity of the interactions between the substrate and the porous AAO film induces different patterns for stress and strain distributions in a nano-porous film as compared to in a solid bare substrate. Under a smaller indentation depth, the effects of the substrate and the porous structure in the AAO film around the indentation are negligible. However, under a larger indentation depth, the effects of the substrate and the porous AAO structure are significant. If the conventional methodology of extrapolating linearly to $h / t=0$ was employed, the values of $E$ and $H$ obtained for porous coatings would be significantly underestimated. Hence, the dilemma of using nanoindentation to extract the mechanical properties of a porous film can be resolved by an alternative (i.e., combined modeling and experimental) approach which could provide a justification by considering the porous structure of the film, minimizing the influence of the substrate, and selecting a proper indentation depth.

\section{Acknowledgement}

This work was supported by the National Science Foundation Grant No. 1462389 and No. 1536209, South Dakota BOR PIF Grant, the Materials Evaluation and Testing Laboratory (METLab), the Department of Mechanical Engineering at South Dakota State University, and the State of South Dakota. Computational facility support from Bryan Rieger at University High Performance Computing, the College of Engineering at South Dakota State University are gratefully acknowledged.

\section{References:}

[1] R. H. Fernando, Chapter 1: Nanocomposites and Nanostructured Coatings: Recent Advancements. In Nanotechnology Applications in Coatings eds. R. H. Fernando, et al., ACS Symposium Series, Washington DC, 2009.

[2] A. Cavaleiro, J. T. M. de Hosson (Eds.), Nanostructured Coatings, Springer, New York, NY, 2006.

[3] El-Sherbiney MGD, Halling J. The Hertzian contact of surfaces covered with metallic films. Wear 40(1976)325-337.

[4] Jönsson B, Hogmark S. Hardness measurements of thin films. Thin Solid Films. 114(3)(1984)257-269.

[5] Sargent PM. Use of indentation size effect in microhardness for materials characterization: in "Microindentation techniques in Materials Science and Engineering", (eds. P. J. Blau and B. R. Lawn), ASTM STP889, 160-174, ASTM, Philadelphia, PA 1986.

[6] Doerner MF, Nix WD. A method for interpreting the data from depth-sensing indentation instruments. J. Mater. Res. 1(4)(1986)601-609. 
[7] Burnet PJ, Rickerby DS. The mechanical properties of wear-resistant coatings: I: Modeling of hardness behavior. Thin Solid Films, 148(1)(1987)41-50.

[8] Burnett PJ, Richerby DS. The mechanical properties of wear-resistance coatings II: Experimental studies and interpretation of hardness. Thin Solid Films, 148(1987)51-65.

[9] King RB. Elastic analysis of some punch problems for a layered medium. International Journal of Solids and Structures, 23(12)1(1987)1657-1664.

[10] Bhattacharya AK, Nix WD. Finite element simulation of indentation experiments. International Journal of Solids and Structures. 24(9)(1988)881-891.

[11] Bhattacharya AK, Nix WD. Analysis of elastic and plastic deformation associated with indentation testing of thin films on substrates. International Journal of Solids and Structures. 24(12)(1988)1287-1298.

[12] Stone D, LaFontaine WR, Alexopolous P, Wu TW, Li CY. An investigation of hardness and adhesion of sputter-deposited aluminum on silicon by utilizing a continuous indentation test. J. Mater. Res., 3(1)(1988)141-147.

[13] Bull SJ, Rickerby DS. New developments in the modeling of the hardness and scratch adhesion of thin films. Surface and Coatings Technology. 42(2)(1990)149-164.

[14] H. Gao, C. Chiu, J. Lee, Elastic contact versus indentation modeling of multi-layered materials, Int. J. Solids Structures, 29(20)(1992)2471-2492.

[15] M. V. Swain, E. R. Weppelmann, A simple method for determination of the elastic modulus of thin films on a substrate, Mat. Res. Soc. Symp. Proc., 308(1993)177-182.

[16] Chechenin NG, Bøttiger J, Krog JP. Nanoindentation of amorphous aluminum oxide films I. The influence of the substrate on the plastic properties. Thin Solid Films 261(1995)219-227.

[17] Chechenin NG, Bøttiger J, Krog JP. Nanoindentation of amorphous aluminum oxide films II. Critical parameters for the breakthrough and a membrane effect in thin hard films on soft substrates. Thin Solid Films 261(1995)228-235.

[18] Schwarzer N, Whittling M, Swain M, Richter F. The analytical solution of the contact problem of spherical indenters on layered materials: application for the investigation of TiN films on silicon. Thin Solid Films, 270(1-2)(1995)371-375.

[19] Chicot D, Lesage J. Absolute hardness of films and coatings. Thin Solid Films, 254(1995)123-130.

[20] Vinci RP, Vlassak JJ. Mechanical behavior of thin films. Annual Review of Materials Science. 26(1996)431462.

[21] Chechenin NG, Bøttiger J, Krog JP. Nanoindentation of amorphous aluminum oxide films III. The influence of the substrate on the elastic properties. Thin Solid Films 304 (1997)70-77.

[22] Li J, Chou TW. Elastic field of a thin film/substrate system under axisymmetric loading. Int. J. Solids Struct. 34(1997)4463-4478.

[23] J. L. Hay, M. E. O'Hern, W. C. Oliver, The importance of contact radius for substrate-independent property measurement of thin films, MRS Proc., 522(1998)27-32.

[24] Hu XZ, Lawn BR. A simple indentation stress-strain relation for contacts with spheres on bilayer structures. Thin Solid Films, 322(1998)225-232.

[25] Korsunsky AM, McGurk MR, Bull SJ, Page TF. On the hardness of coated systems. Surface and Coatings Technology, 99(1998)171-183.

[26] McGurk MR, Page TF. Using the P- $\delta^{2}$ analysis to deconvolute the nanoindentation response of hard-coated systems. Journal of Materials research, 14(6)(1999)2283-2295.

[27] Tsui TY, Pharr GM. Substrate effects on nanoindentation mechanical property measurement of soft films on hard substrates. Journal of Materials Research, 14(1)(1999)292-301.

[28] Chudoba T, Schwarzer N, Richter F. Determination of elastic properties of thin films by indentation measurements with a spherical indenter. Surface and Coatings Technology, 127(1)(2000)9-17.

[29] Tuck JR, Korunsky AM, Davidson RJ, Bull SJ, Elliott DM. Modelling of the hardness of electroplated nickel coatings on copper substrates. Surface and Coatings Technology, 127(2000)1-8.

[30] Ohmura T, Matruoka S, Tanaka K, Yoshida T. Nanoindentation load-displacement behavior of pure face centered cubic metal thin films on a hard substrate. Thin Solid Films, 385(2001)198-204.

[31] Saha R, Nix WD. Soft films on hard substrates - nanoindentation of tungsten films on sapphire substrates. Materials Science and Engineering A, 319-321(2001)898-901.

[32] Jennett NM, Bushby AJ. Adaptive Protocol for Robust Estimates of Coatings Properties by Nanoindentation. In MRS Proceedings Volume 695 Symposium L - Thin Films: Stresses and Mechanical Properties IX (Editors: R. C. Cammarata, L. B. Freund, H. Gao, C. S. Ozkan). 2001. Boston.

[33] Bull SJ. Interface engineering and graded films: structure and characterization. J Vac Sci Technol., A19(4)(2001)1401-1414. 
[34] Alcalá G, Skeldon P, Thompson GE, Mann AB, Habazaki H, Shimizu K. Mechanical properties of amorphous anodic alumina and tantala films using nanoindentation. Nanotechnology, 13(2002)451-455.

[35] Puchi-Cabrera ES, Berrios JA, Teer DG. On the computation of the absolute hardness of thin solid films. Surface and Coatings Technology, 157(2002)185-196.

[36] Puchi-Cabrera ES. A new model for the computation of the composite hardness of coated systems. Surface and Coatings Technology, 160(2002)177-186.

[37] Bhushan B, Li X. Nanomechanical characterization of solid surfaces and thin films. International Materials Reviews, 48(3)(2003)125-164.

[38] Beegan D, Chowdlury S, Laugier MT. A nanoindentation study of copper films on oxidized silicon substrates. Surface and Coatings Technology, 176(2003)124-130.

[39] Bull SJ. Modelling of the mechanical and tribological properties of coatings and surface treatments. Mat. Res. Symp. Proc., 750(2003)Y6.1(12 pages).

[40] Tsui TY, Ross CA, Pharr GM. A method for making substrate-independent hardness measurements of soft metallic films on hard substrates by nanoindentation. J. Mater. Res., 18(6)(2003)1383-1391.

[41] Jung YG, Lawn BR, Martyniuk M, Huang H, Hu XZ. Evaluation of elastic modulus and hardness of thin films by nanoindentation. J. Mater. Res., 19(10)(2004)3076-3080.

[42] Chen S, Liu L, Wang T. Size dependent nanoindentation of a soft film on a hard substrate. Acta Materialia, 52(2004)1089-1095.

[43] Xia Z, Riester L, Sheldon BW, Curtin WA, Liang J, Yin A, Xu JM. Mechanical properties of highly ordered nanoporous anodic alumina membranes. Rev. Adv. Mater. Sci. 6(2004)131-139.

[44] Perriot A, Barthel E. Elastic contact to a coated half-space: Effective elastic modulus and real penetration. J. Mater. Res. 102(2004)600-608.

[45] Bull SJ. Topical review: Nanoindentation of coatings. J. Phys. D: Appl. Phys., 38(2005)R393-R413.

[46] Ni W, Cheng YT. Modelling conical indentation in homogenous materials and in hard films on soft substrates. J. Mater. Res., 20(2)(2005)521-528.

[47] Fischer-Cripps AC, Karvánková P, Vepřek S. On the measurement of hardness of super-hard coatings. Surface \& Coatings Technology, 200(2006)5645-5654.

[48] Lu C, Mai YW. Recent advances on understanding the origin of superhardness in nanocomposites coatings: a critical review. J. Mater. Sci., 41(2006)937-950.

[49] Fang TH, Chang WJ, Lin CM. Nanoindentation characterization of $\mathrm{ZnO}$ thin films. Materials Science and Engineering A, 452-453(2007)715-720.

[50] ISO 14577-4:2007 Metallic materials - Instrumented indentation test for hardness and materials parameters Part 4: Test method for metallic and non-metallic coatings, 2007. https://www.iso.org/obp/ui/\#iso:std:39228:en.

[51] Kizler P, Schmauder S. Simulation of the nanoindentation of hard metal carbide layer systems - the case of nanostructured ultra-hard carbide layer systems. Computational Materials Science, 39(2007)205-213.

[52] Bourhis EL. Indentation mechanics and its application to thin film characterization. Vacuum, 82(2008)13531359.

[53] Wang CT, Jian SR, Jang JSC, Lai YS, Yang PF. Multiscale simulation of nanoindentation on Ni (100) thin film. Applied Surface Science, 255(2008)3240-3250.

[54] Chen KS, Chen TC, Ou KS. Development of semi-empirical formulation for extracting materials properties from nanoindentation measurements: residual stresses, substrate effect, and creep. Thin Solid Films, 516(2008)1931-1940.

[55] Pelegri AA, Huang X. Nanoindentation on soft film/hard substrate and hard film/soft substrate material systems with finite element analysis. Composites Science and Technology, 68(2008)147-155.

[56] Peng P, Liao G, Shi T, tang Z, Gao Y. Molecular dynamics simulations of nanoindentation in aluminum thin film on silicon substrate. Applied Surface Science, 256(2010)6284-6290.

[57] Hay J, Crawford B. Measuring substrate-independent modulus of thin films. J. Mater. Res., 26(6)(2011)727738.

[58] Fischer-Cripps AC. (Ed.), Nanoindentation, 3rd edition, Springer, New York, NY, 2011.

[59] Bull SJ. Chapter 7 Nanoindentation Measurements of Mechanical Properties of Very Thin Films and Nanostructured Materials at High Spatial Resolution, in Scanning Probe Microscopy in Industrial Applications: Nanomechanical Characterization, Edited by Dalia G. Yablon, published by Wiley \& Sons, Inc., Hoboken, New Jersey, USA, 2014.

[60] Homier R, Jaouad A, Turala A, Valdivia CE, Masson D, Wallace SG, Fafard S, Arès R, Aimez V. Antireflection coating design for triple-junction III-V/Ge high-efficiency solar cells using low absorption PECVD silicon nitrode. IEEE Journal of Photovoltaics, 2(3)(2012)393-397. 
[61] Yang TC, Lee BS, Yen TJ. Minimizing reflection losses from metallic electrodes and enhancing photovoltaic performance using the Si-micrograting solar cell with vertical sidewall electrodes. Appl. Phys. Lett., 101(10)(2012)103902.

[62] Selj JH, Thøgersen A, Foss SE, Marstein ES. Optimization of multilayer porous silicon antireflection coatings for silicon solar cells. J. Appl. Phys., 107(7)(2010)074904.

[63] Yeh YCM, Ernest FP, Stirn RJ. Practical antireflection coatings for metal-semiconductor solar cells. J Appl. Phys., 47(9)(1976)4107-4112.

[64] Chhajed S, Schubert MF, Kim JK, Fred Schubert E. Nanostructured multilayer graded-index antireflection coating for $\mathrm{Si}$ solar cells with broadband and omnidirectional characteristics. Appl. Phys. Lett., 93(25)(2008)251108-251108-3.

[65] Mandal N, Dubey M, Gupta RK, Ghimire B, Galipeau D, Fan QH. Structures and optical properties of anodic aluminum oxide thin films. J Coating Sci. Technol., 1(1)(2014)1-9.

[66] Chen J, Wang B, Yang Y, Shi Y, Xu G, Cui P. Porous anodic alumina with low refractive index for broadband graded-index antireflection coatings. Applied Optics, 51(28)(2012)6839-6843.

[67] He Y, Li X, Que L. Fabrication and characterization of lithographically patterned and optically transparent anodic aluminum oxide (AAO) nanostructure thin film. J Nanosic Nanotechnol., 12(10)(2012)7915-7921.

[68] Liu S, Xiong Z, Zhu C, Li M, Zheng M, Shen W. Fast anodization fabrication of AAO and barrier perforation process on ITO glass. Nanoscale Research Letters, 9(2014)159(8 pages).

[69] Yakovleva NM, Yakivlev AN, Chupakhina EA. Structural analysis of alumina films produced by two-step electrochemical oxidation. Thin Solid Films 366(2000)37-42.

[70] Brown IWM, Bowden ME, Kemmitt T, MacKenzie KJD. Structural and thermal characterisation of nanostructured alumina templates. Current Applied Physics 6(2006)557-561.

[71] Lu C, Chen Z. Anodic aluminum Oxide-Based Nanostructures and Devices. Encyclopedia of Nanoscience and Nanotechnology (Edited by H. S. Nalwa) Volume 11(2011)235-259.

[72] Poinern GEJ, Ali N, Fawcett D. Progress in nano-engineered anodic aluminum oxide membrane development. Materials 4(2011)487-526.

[73] W. C. Oliver, G. M. Pharr, An improved technique for determining hardness and elastic modulus using load and displacement sensing indentation experiments, J. Mater. Res., 7(1992)1564-1583.

[74] Oliver WC, Pharr GM. Measurement of hardness and elastic modulus by instrumented indentation: advances in understanding and refinement to methodology. Journal of Materials Research, 19(1)(2004)3-20.

[75] ANSYS Inc., ANSYS Theory Reference Manual - ANSYS version 14.5, 2013.

[76] Wolfenden A. Measurement and analysis of elastic and anelastic properties of alumina and silicon carbide. Journal of Materials Science, 32(1997)2275-2282.

[77] Silva ECCM. Effects of water on chemomechanical instabilities in amorphous silica: Nanoscale experiments and molecular simulation. Ph.D. Dissertation, Massachusetts Institute of Technology, Massachusetts, USA, 2007.

[78] Sánchez-González E, Miranda P, Meléndez-Martínez JJ, Guiberteau F, Pajares A. Temperature dependence of mechanical properties of alumina up to the onset of creep. Journal of European Ceramic Society, 27(2007)3345-3349.

[79] Liu B, Wang JY, Zhou YC, Li FZ. Temperature dependence of elastic properties for amorphous $\mathrm{SiO} 2$ by Molecular Dynamics Simulation. Chin. Phys. Lett., 25(8)(2008)2747-2750.

[80] Yagnamurthy S, Chasiotis I, Lambros J, Polcawich R, Pulskamp J, Dubey M. Mechanical Properties of PZT films and their composites for RF-MEMS. Proceedings of the XIth International Congress and Exposition, June 2-5, 2008 Orlando, Florida, USA. (7 pages)

[81] Carlsson S, Biwa S, Larsson PL. On frictional effects at inelastic contact between spherical bodies. Int. J. Mech. Sci., 42(2000)107-128.

[82] Mata M, Alcalá J. The role of friction on sharp indentation. Journal of the Mechanics and Physics of Solids, 52(2004)145-165.

[83] Guo WC, Ponthot J-P, Zhang WH, Ranchs G. The influence of friction on elasto-plastic material in nanoindentation. Proceedings of ACOMEN'2008, Advanced Computational Methods in Engineering, 2008 (14 pages).

[84] Hu Z, Lynne KJ, Markondapatnaikuni SP, Delfanian F. Material elastic-plastic property characterization by nanoindentation testing coupled with computer modeling. Materials Science \& Engineering A, 587(2013)268282.

[85] $\mathrm{Hu}$ Z, Farahikia M, Delfanian F. Fiber bias effect on characterization of carbon fiber-reinforced polymer composites by nanoindentation testing and modeling. Journal of Composite Materials, Published online before print, December 3, 2014, doi:10.1177/0021998314562221. 
[86] Hu Z, Lynne K, Delfanian F. Characterization of materials' elasticity and yield strength through micro-/nanoindentation testing with a cylindrical flat-tip indenter. Journal of Materials Research, accepted 2014.

[87] K. Tapily, J. E. Jakes, D. S. Stone, P. Shrestha, D. Gu, H. Baumgart, A. A. Elmustafa, Nanoindentation investigation of $\mathrm{HfO} 2$ and $\mathrm{A} 12 \mathrm{O} 3$ films grown by atomic layer deposition, Journal of the Electrochemical Society, 155(7)(2008)H545-H551.

[88] S. Ruppi, A. Larsson, A. Flink, Nanoindentation hardness, texture and microstructure of $\alpha-\mathrm{Al} 2 \mathrm{O} 3$ and $\kappa-$ Al2O3 coatings, Thin Solid Films, 516(2008)5959-5966. 


\section{List of Table Captions:}

Table 1: Nanoindentation testing data.

Table 2: Nanoindentation modeling data.

\section{List of Figure Captions:}

Figure 1: Schematic diagram of fabrication procedure of porous anodic aluminum oxide [65].

Figure 2: The resulted AAO coating sample: (a) SEM image of the surface morphology, (b) SEM image of the cross section, and (c) 3D laser microscope image of the cross section porosity profile.

Figure 3: SEM image of the upward view of the Berkovich indenter's sharp tip 3-sided pyramidal geometry.

Figure 4: SEM image of Berkovich impressions on the porous AAO thin film coated on the glass slide substrate (corresponding to a maximum indentation load of $40 \mathrm{mN}$ ).

Figure 5: Indentation load vs. depth curve of the AAO coating.

Figure 6: 3D view of meshed nanoindentation models. (a) Glass slide only, and (b) porous AAO coating on glass substrate.

Figure 7: Data comparison of modelings with experiments of the porous AAO coating on glass substrate at different indentation depths: (a) Young's modulus, and (b) hardness.

Figure 8: von Mises stress (MPa) distributions at different indentation depths: (a) $50 \mathrm{~nm}$ on glass slide, (b) $50 \mathrm{~nm}$ on AAO coating on glass substrate, (c) $250 \mathrm{~nm}$ on glass slide, and (d) $250 \mathrm{~nm}$ on AAO coating on glass substrate.

Figure 9: von Mises strain distributions at different indentation depths: (a) $50 \mathrm{~nm}$ on glass slide, (b) $50 \mathrm{~nm}$ on AAO coating on glass substrate, (c) $250 \mathrm{~nm}$ on glass slide, and (d) 250 nm on AAO coating on glass substrate. 
Table 1: Nanoindentation testing data.

\begin{tabular}{|c|c|c|c|c|c|c|c|c|c|c|}
\hline \multicolumn{11}{|c|}{ (a) Glass slide only } \\
\hline & Ave. & St. Dev. & Ave. & St. Dev. & Ave. & St. Dev. & Ave. & St. Dev. & Ave. & St. Dev. \\
\hline$h_{\max }(\mathrm{nm})$ & 209.1 & 1.39 & 325.9 & 3.20 & 506.2 & 4.97 & 687.9 & 34.2 & 822.8 & 13.8 \\
\hline$P_{\max }(\mathrm{mN})$ & 10.04 & 0.0200 & 20.10 & 0.0512 & 40.25 & 0.075 & 60.17 & 0.0566 & 80.36 & 0.0495 \\
\hline$S(\mathrm{mN} / \mu \mathrm{m})$ & 84.40 & 2.15 & 112.0 & 3.05 & 161.1 & 2.91 & 185.3 & 0.919 & 215.1 & 0.990 \\
\hline$h(\mathrm{~nm})$ & 119.8 & 3.49 & 191.2 & 6.30 & 318.8 & 7.93 & 444.3 & 35.2 & 542.7 & 12.3 \\
\hline$A\left(\mu \mathrm{m}^{2}\right)$ & 1.125 & 0.0360 & 1.967 & 0.0845 & 4.046 & 0.152 & 5.852 & 0.766 & 7.216 & 0.327 \\
\hline$E_{r}(\mathrm{GPa})$ & 70.53 & 0.709 & 70.75 & 0.626 & 70.98 & 0.271 & 74.87 & 5.56 & 70.99 & 1.94 \\
\hline$E(\mathrm{GPa})$ & 72.99 & 0.783 & 73.23 & 0.690 & 73.48 & 0.299 & 77.80 & 6.18 & 73.50 & 2.14 \\
\hline$H(\mathrm{GPa})$ & 8.935 & 0.283 & 10.23 & 0.420 & 9.957 & 0.363 & 12.56 & 1.97 & 11.15 & 0.499 \\
\hline \multicolumn{11}{|c|}{ (b) AAO film on glass substrate } \\
\hline$h_{\max }(\mathrm{nm})$ & 257.9 & 36.8 & 342.8 & 16.0 & 505.8 & 21.0 & 652.9 & 38.1 & 839.3 & 61.0 \\
\hline$P_{\max }(\mathrm{mN})$ & 4.999 & 0.0742 & 10.06 & 0.0427 & 14.99 & 0.0337 & 20.05 & 0.0359 & 40.18 & 0.0556 \\
\hline$S(\mathrm{mN} / \mu \mathrm{m})$ & 137.5 & 15.0 & 162.0 & 13.6 & 188.1 & 5.54 & 220.5 & 3.49 & 255.3 & 4.58 \\
\hline$h(\mathrm{~nm})$ & 230.4 & 39.2 & 296.0 & 16.6 & 446.0 & 21.5 & 584.7 & 37.7 & 721.2 & 61.8 \\
\hline$A\left(\mu \mathrm{m}^{2}\right)$ & 1.334 & 0.487 & 2.152 & 0.241 & 4.882 & 0.467 & 8.402 & 1.08 & 12.81 & 2.10 \\
\hline$E_{r}(\mathrm{GPa})$ & 107.7 & 6.46 & 98.16 & 8.55 & 75.65 & 3.56 & 67.75 & 4.81 & 63.73 & 5.48 \\
\hline$E(\mathrm{GPa})$ & 113.7 & 7.49 & 102.7 & 9.76 & 77.43 & 3.91 & 68.85 & 5.18 & 64.53 & 5.89 \\
\hline$H(\mathrm{GPa})$ & 4.075 & 1.03 & 4.722 & 0.550 & 3.094 & 0.304 & 2.417 & 0.313 & 3.211 & 0.616 \\
\hline
\end{tabular}

Table 2: Nanoindentation modeling data.

\begin{tabular}{|c|c|c|c|c|c|c|c|c|c|c|c|c|c|c|c|c|c|c|c|c|c|}
\hline \multicolumn{22}{|c|}{ (a) Glass slide only } \\
\hline$h_{\max }(\mathrm{nm})$ & 11.5 & 21.5 & 31.5 & 41.5 & 51.5 & 61.5 & 71.5 & 81.5 & 91.5 & 102 & 122 & 147 & 172 & 197 & 250 & 300 & 35 & 400 & 450 & 50 & 600 \\
\hline$P_{\max }(\mathrm{mN})$ & 0.012 & 0.057 & 0.126 & 0.219 & 0.336 & 0.478 & 0.647 & 0.839 & 1.06 & 1.30 & 1.86 & 2.71 & 3.71 & 4.86 & 7.86 & 11.2 & 15. & 20.1 & 25.4 & 31.2 & 45.3 \\
\hline$S(\mathrm{mN} / \mu \mathrm{m})$ & 2.75 & \begin{tabular}{|l|}
5.25 \\
\end{tabular} & 7.34 & 9.62 & 12.1 & 14.5 & 16.8 & 19.3 & 21.6 & 24.0 & 28.8 & 34.8 & 40.9 & 46.8 & 59.7 & 72.6 & 84. & 95.0 & 107 & 119 & 143 \\
\hline$h(\mathrm{~nm})$ & 6.97 & 13.3 & 18.6 & 24.4 & 30.7 & 36.8 & 42.7 & 48.8 & 54.7 & 60.9 & 73.0 & 88.2 & 103 & 119 & 151 & 184 & 21 & 241 & 273 & 302 & 362 \\
\hline$A\left(\mu \mathrm{m}^{2}\right) \times 10^{-3}$ & 1.19 & 4.35 & 8.49 & 14.6 & 23.2 & 33.3 & 44.7 & 58.4 & 73.3 & 91.0 & 131 & 190 & 262 & 344 & 560 & 829 & 111 & 1423 & 1820 & 223 & 3203 \\
\hline$E_{r}(\mathrm{GPa})$ & 70.7 & 70.6 & 70.6 & 70.6 & 70.6 & 70.7 & 70.6 & 70.6 & 70.7 & 70.6 & 70.6 & 70.6 & 70.6 & 70.6 & 70.6 & 70.6 & 70. & 70.6 & 70.6 & 70. & 70.6 \\
\hline$E(\mathrm{GPa})$ & 73.1 & 73.1 & 73.1 & 73.1 & 73.1 & 73.1 & 73.1 & 73.1 & 73.1 & 73.1 & 73.1 & 73.1 & 73.1 & 73.1 & 73.1 & 73.1 & 73. & 73.1 & 73.1 & 73. & 73.1 \\
\hline$H(\mathrm{GPa})$ & 13.9 & 13.2 & 14.9 & 15.1 & 14.5 & 14.4 & 14.5 & 14.4 & 14.4 & 14.3 & 14.3 & 14.2 & 14.2 & 14.1 & 14.0 & 13.6 & 13. & 14.2 & 14.0 & 14. & 14.1 \\
\hline \multicolumn{22}{|c|}{ (b) AAO film on glass substrate } \\
\hline$h_{\max }(\mathrm{nm})$ & & 1.5 & 21.5 & & 46.5 & 71.5 & & 96.5 & & 122 & & \begin{tabular}{l|l}
47 & \\
\end{tabular} & 197 & & 247 & \multicolumn{2}{|c|}{297} & 400 & \multicolumn{2}{|c|}{500} & 600 \\
\hline$P_{\max }(\mathrm{mN})$ & 0.02 & & 0.0813 & & 0.337 & 0.709 & & 1.20 & & 1.76 & & 43 & 3.98 & & 5.72 & \multicolumn{2}{|c|}{7.64} & 11.8 & \multicolumn{2}{|c|}{16.1} & 21.5 \\
\hline$S(\mathrm{mN} / \mu \mathrm{m})$ & & 3.7 & 22.9 & & 42.8 & 55.7 & & 65.3 & & 74.1 & & 2.5 & 99.7 & & 118 & \multicolumn{2}{|c|}{135} & 155 & \multicolumn{2}{|c|}{177} & 199 \\
\hline$h(\mathrm{~nm})$ & & 0.0 & 18.8 & & 40.6 & 62.0 & & 82.7 & & 104 & & 24 & 167 & & 210 & \multicolumn{2}{|c|}{254} & 343 & \multicolumn{2}{|c|}{432} & 519 \\
\hline$A\left(\mu \mathrm{m}^{2}\right) \times 10^{-3}$ & & .47 & 8.70 & & 40.3 & 94.0 & & 167 & & 263 & & 79 & 680 & & 1080 & \multicolumn{2}{|c|}{1580} & 2880 & \multicolumn{2}{|c|}{4570} & 6590 \\
\hline$E_{r}(\mathrm{GPa})$ & & 244 & 218 & & 189 & 161 & & 141 & & 128 & & 19 & 107 & & 101 & \multicolumn{2}{|c|}{95.2} & 80.9 & \multicolumn{2}{|c|}{73.4} & 68.5 \\
\hline$E(\mathrm{GPa})$ & & 296 & 257 & & 216 & 179 & & 154 & & 138 & & 27 & 113 & & 106 & \multicolumn{2}{|c|}{99.2} & 83.2 & \multicolumn{2}{|c|}{75.0} & 69.7 \\
\hline$H(\mathrm{GPa})$ & & 0.8 & 9.34 & & 8.36 & 7.54 & & 7.20 & & 6.70 & & 41 & 5.85 & & 5.28 & \multicolumn{2}{|c|}{4.83} & 4.10 & \multicolumn{2}{|c|}{3.52} & 3.26 \\
\hline
\end{tabular}




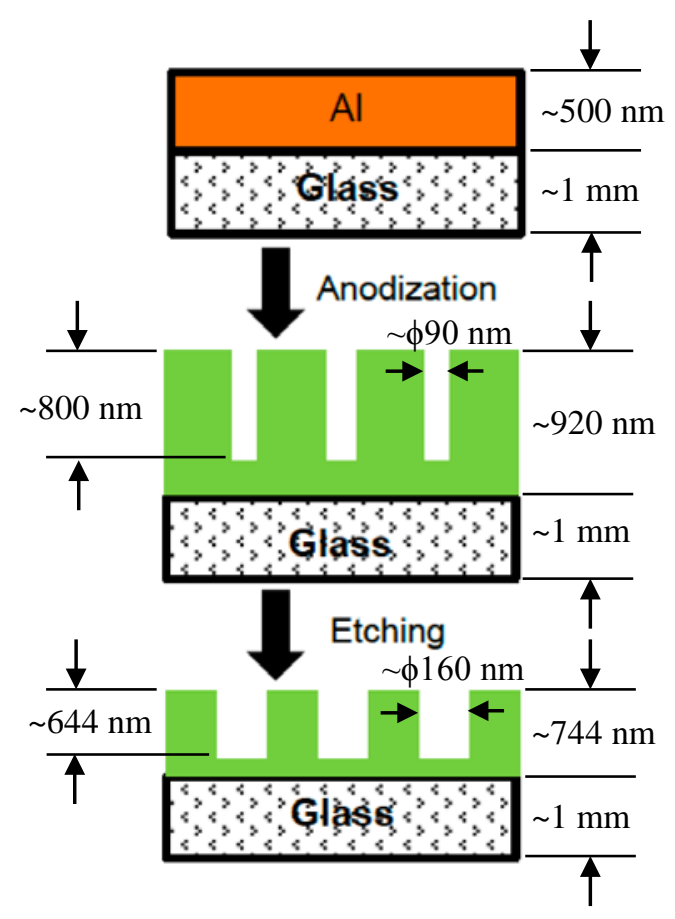

Figure 1: Schematic diagram of fabrication procedure of porous anodic aluminum oxide [65]. 


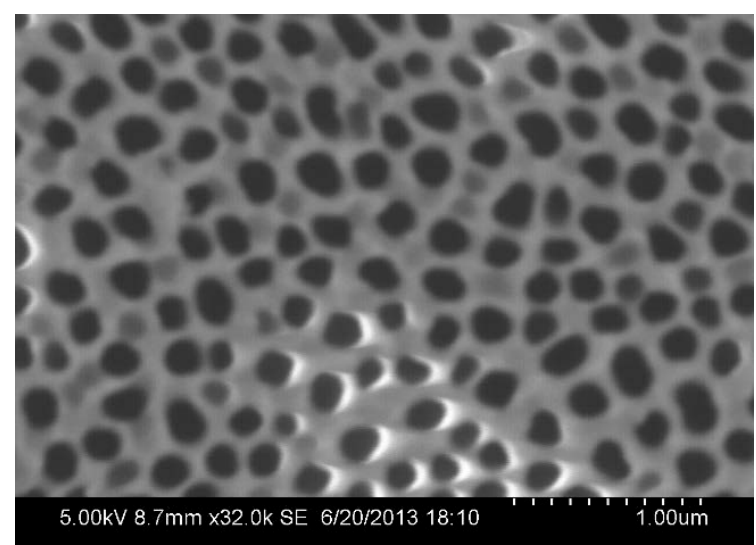

(a)

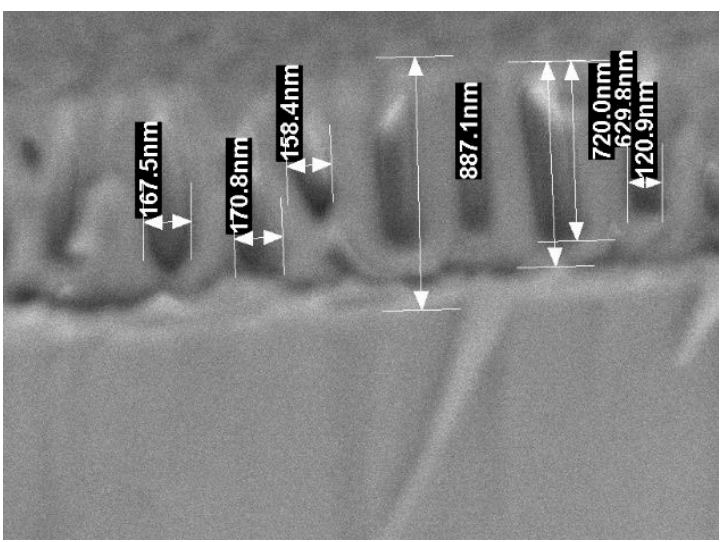

(b)

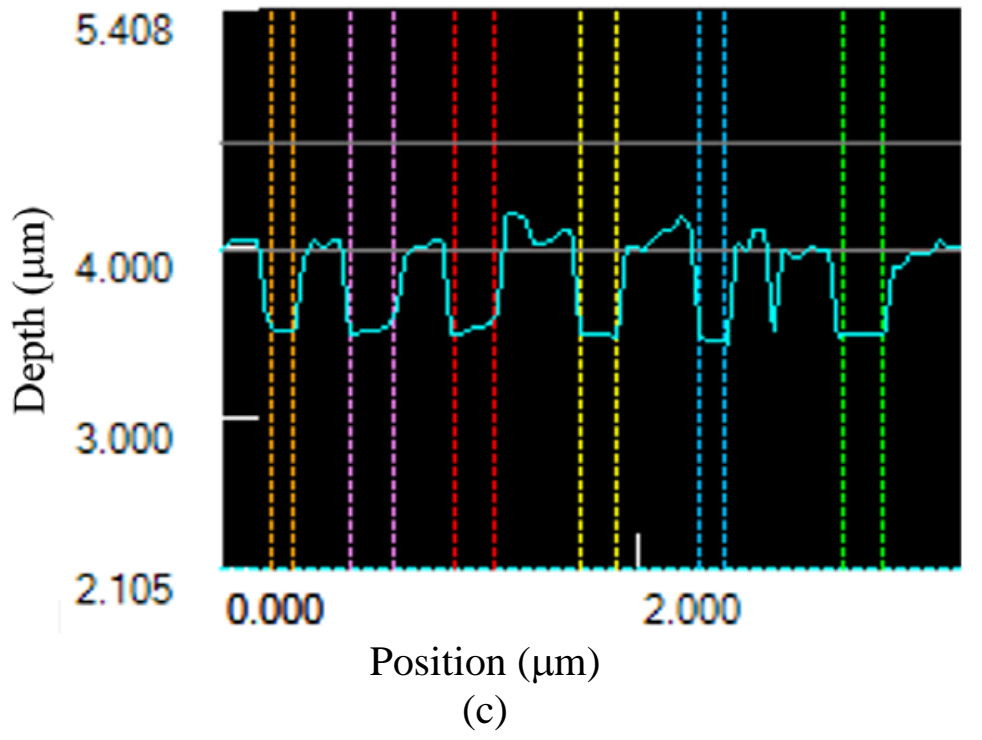

Figure 2: The resulted AAO coating sample: (a) SEM image of the surface morphology, (b) SEM image of the cross section, and (c) 3D laser microscope image of the cross section porosity profile. 


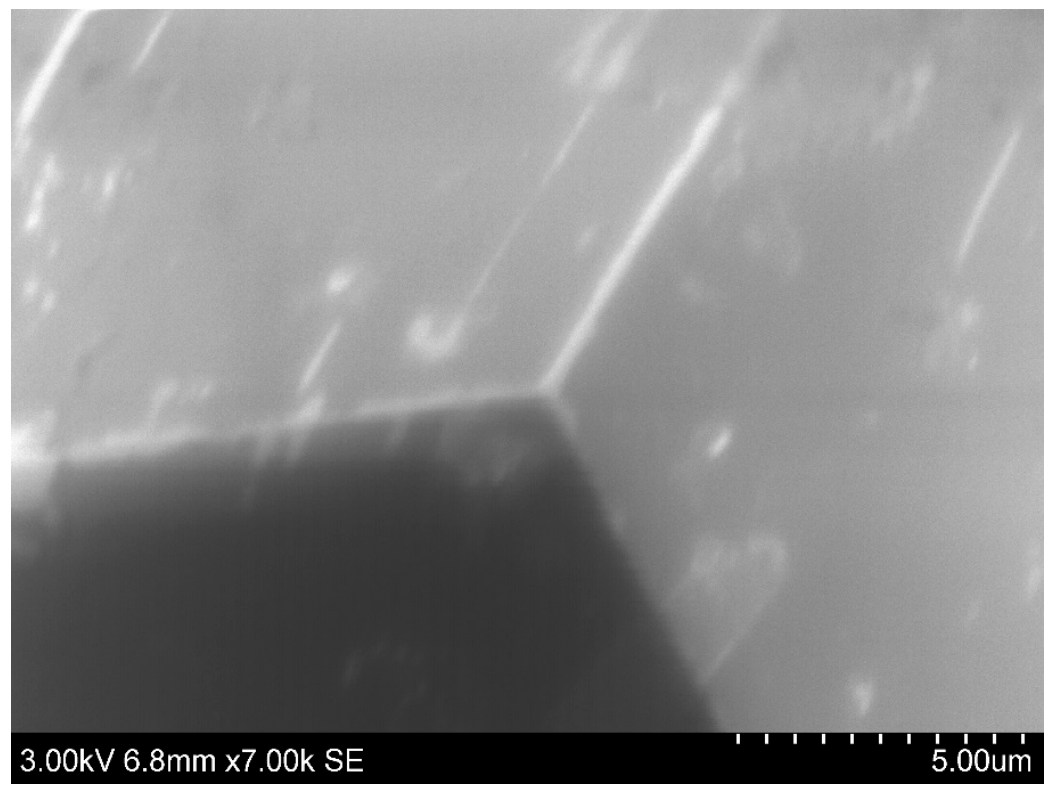

Figure 3: SEM image of the upward view of the Berkovich indenter's sharp tip 3-sided pyramidal geometry. 


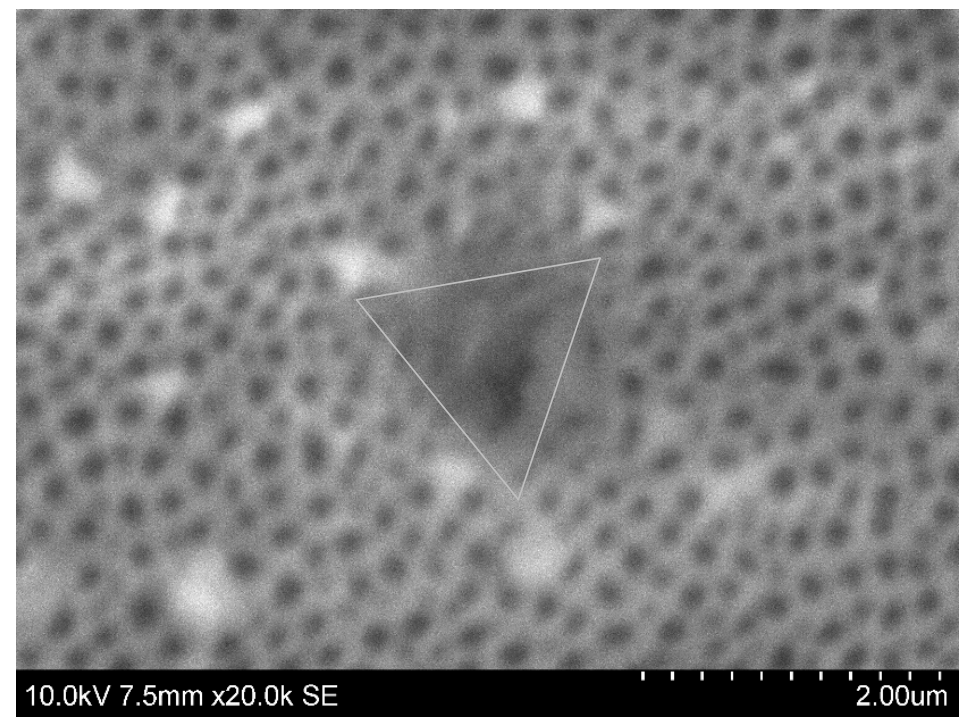

Figure 4: SEM image of Berkovich impressions on the porous AAO thin film coated on the glass slide substrate (corresponding to a maximum indentation load of $40 \mathrm{mN}$ ). 


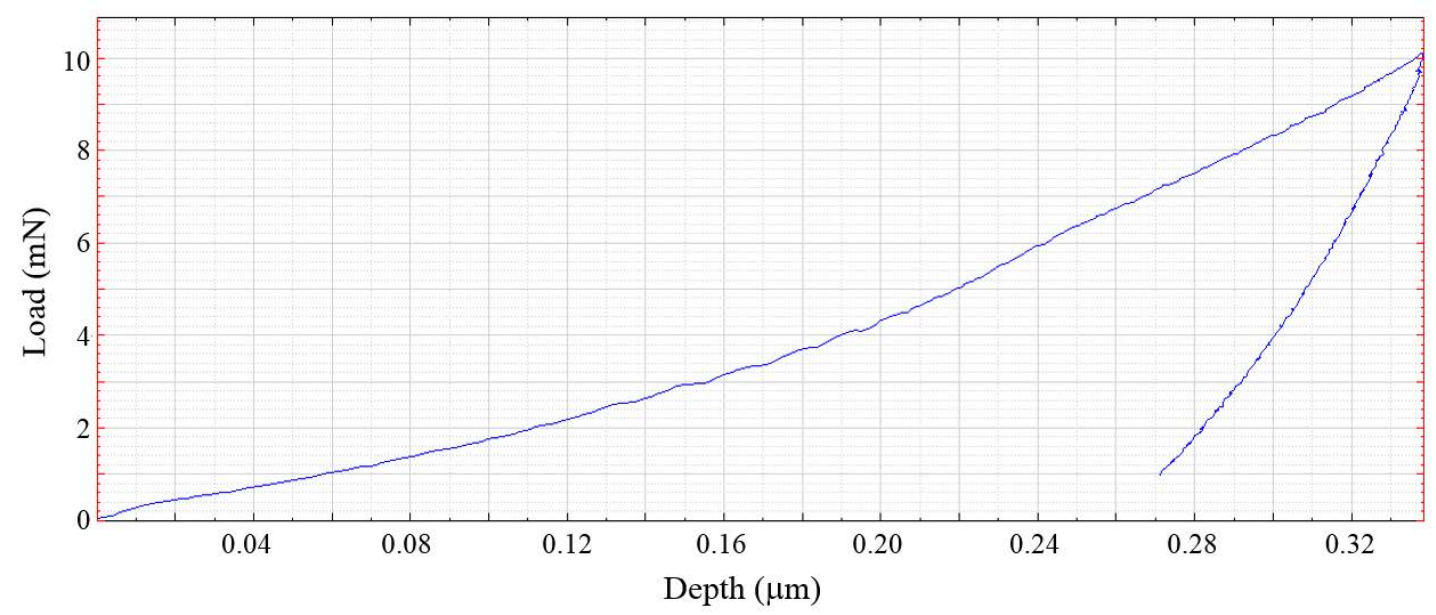

Figure 5: Indentation load vs. depth curve of the AAO coating. 


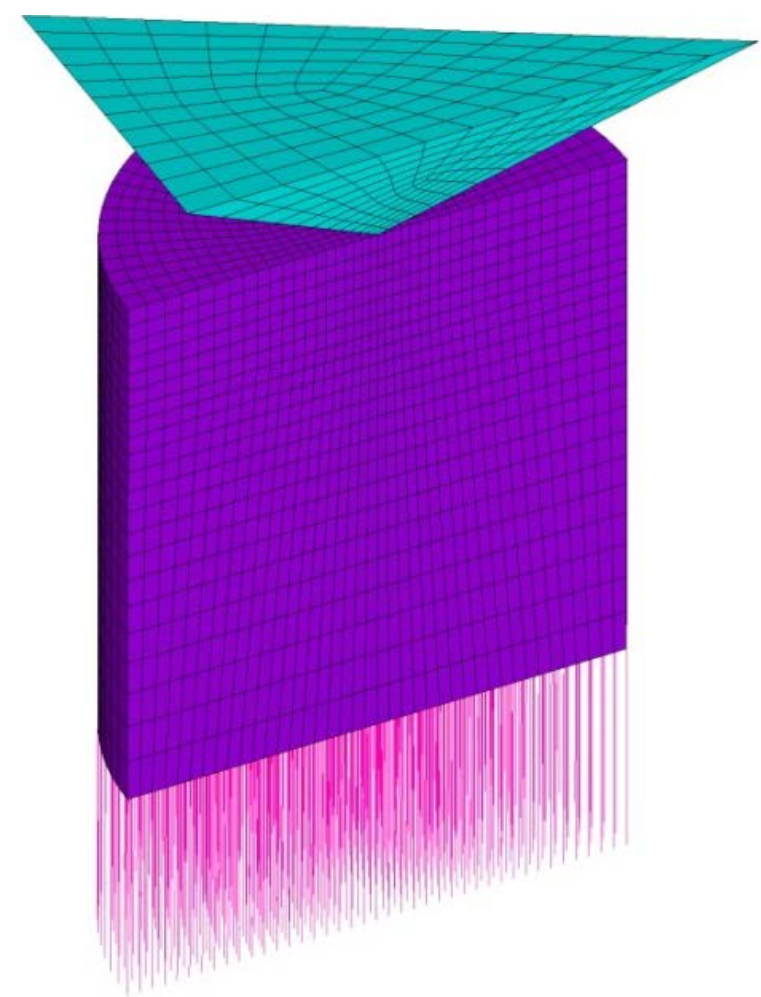

(a)

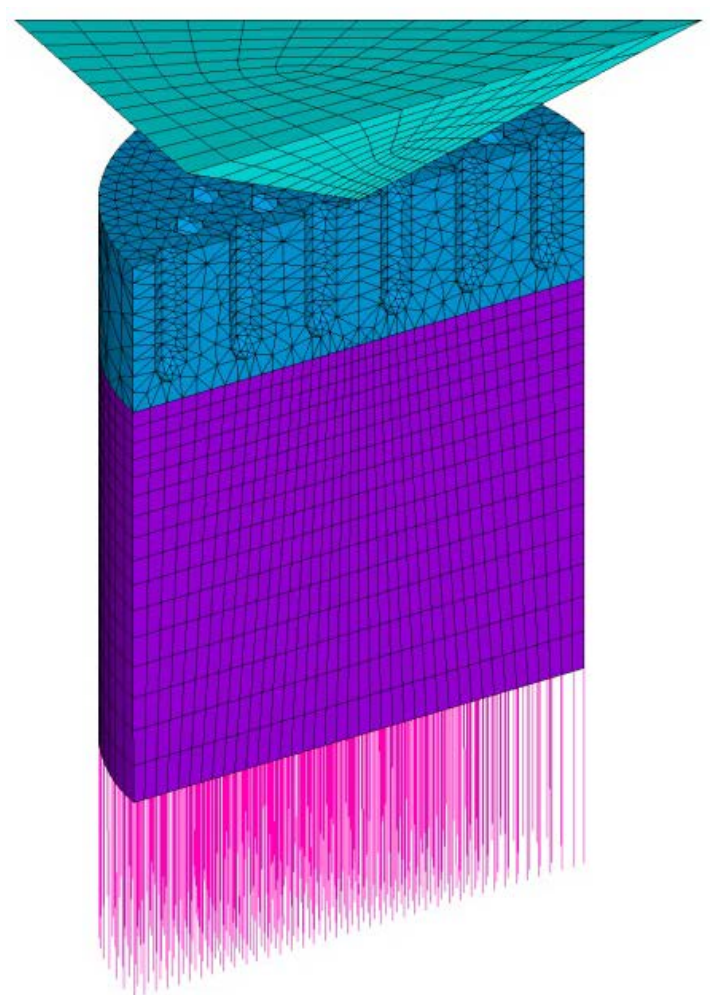

(b)

Figure 6: 3D view of meshed nanoindentation models. (a) Glass slide only, and (b) porous AAO coating on glass substrate. 


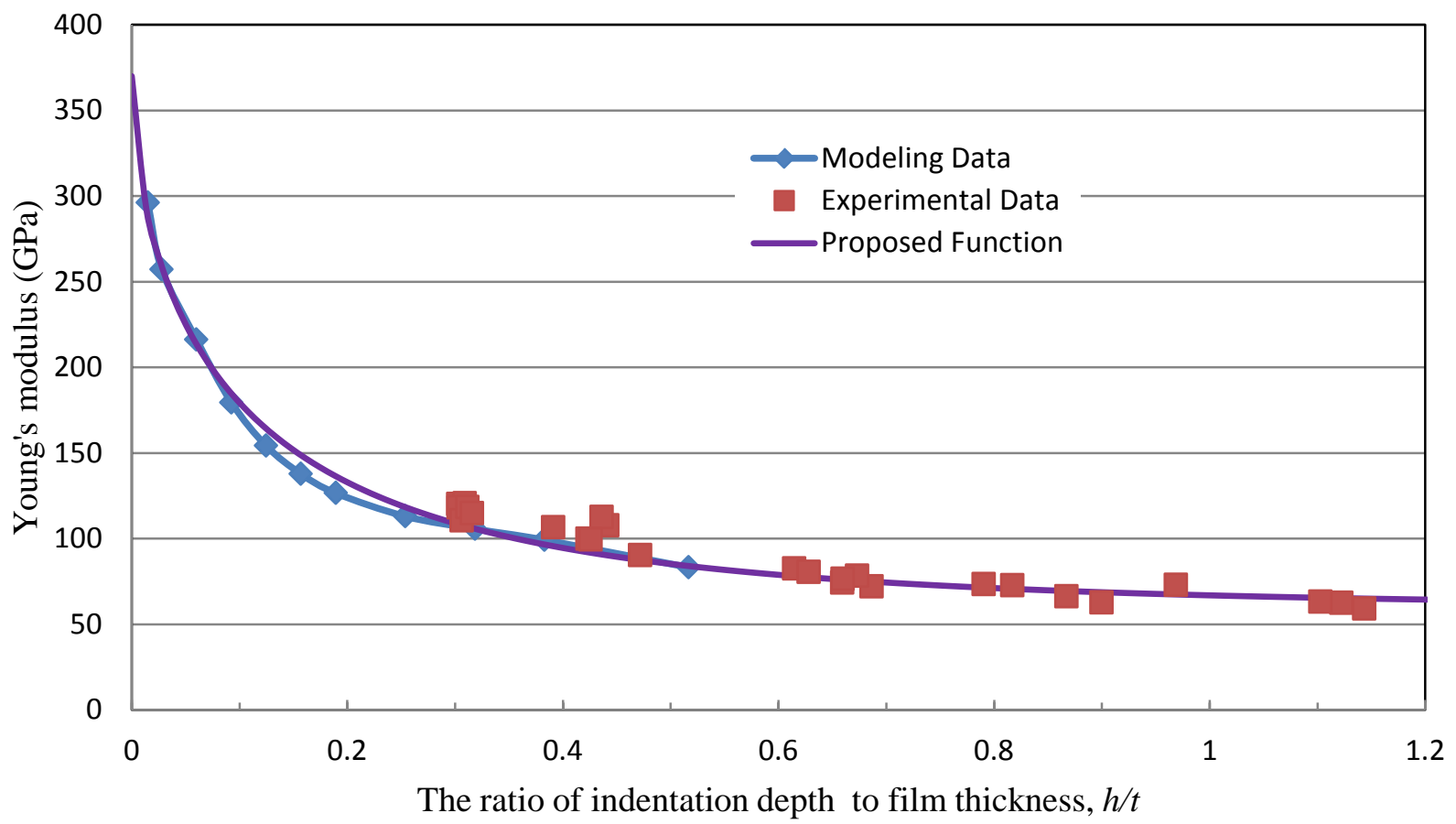

(a)

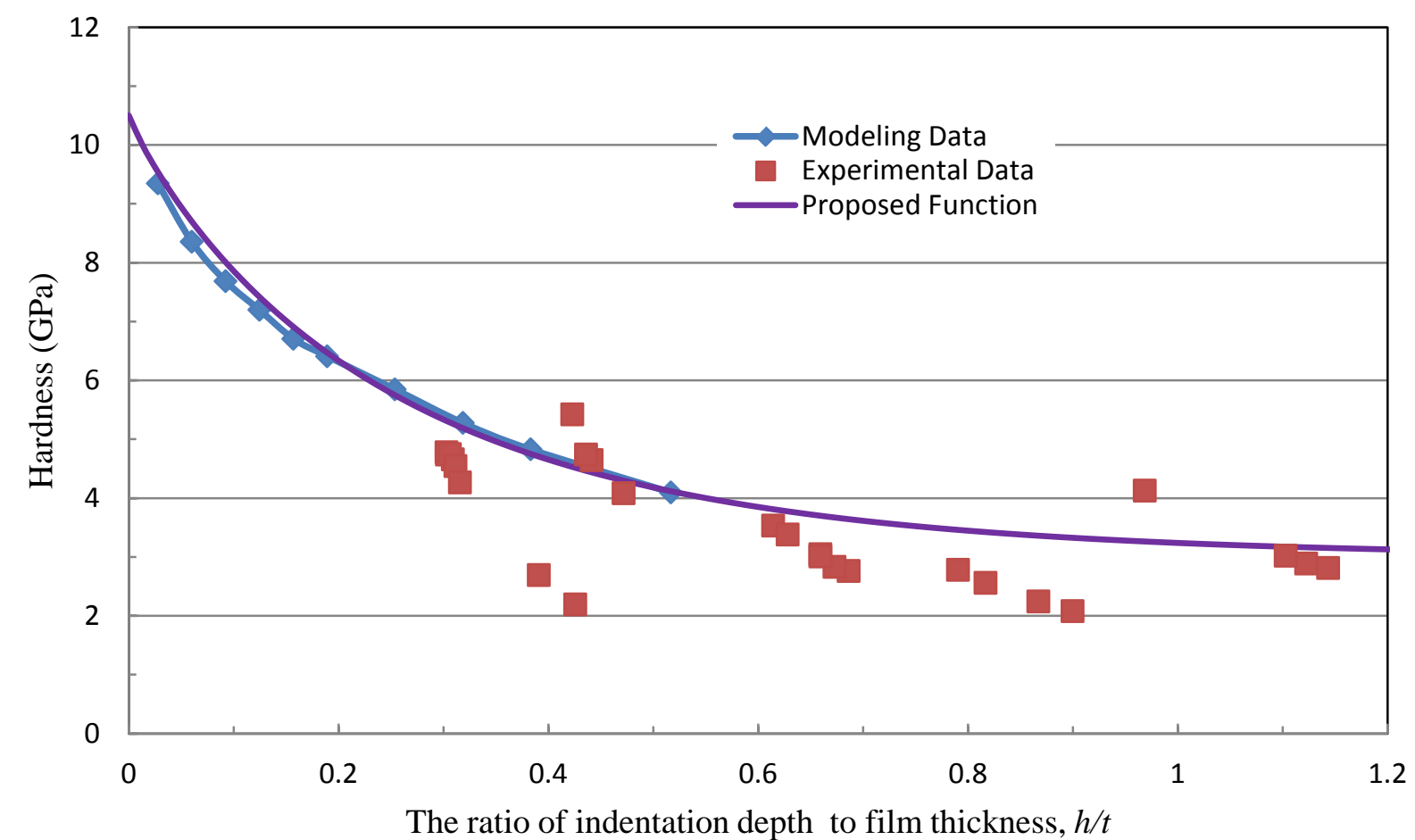

(b)

Figure 7: Data comparison of modelings with experiments of the porous AAO coating on glass substrate at different indentation depths: (a) Young's modulus, and (b) hardness. 


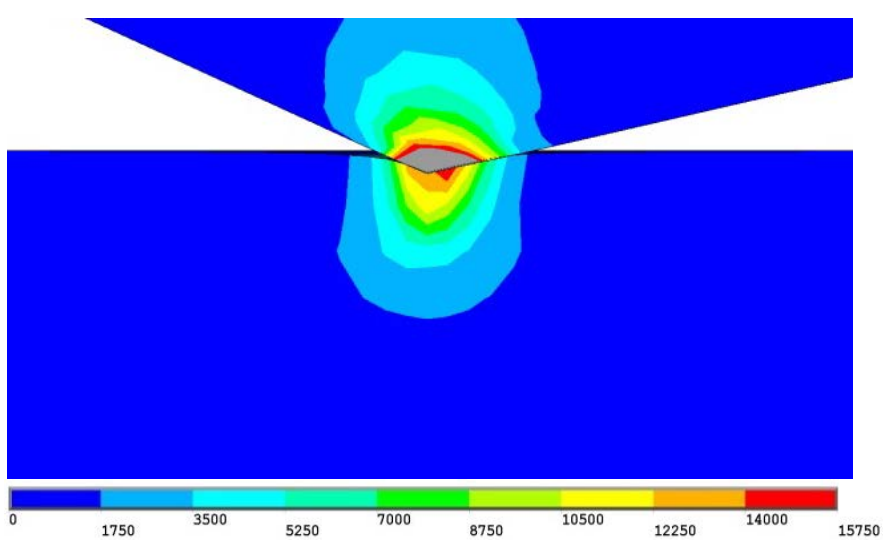

(a)

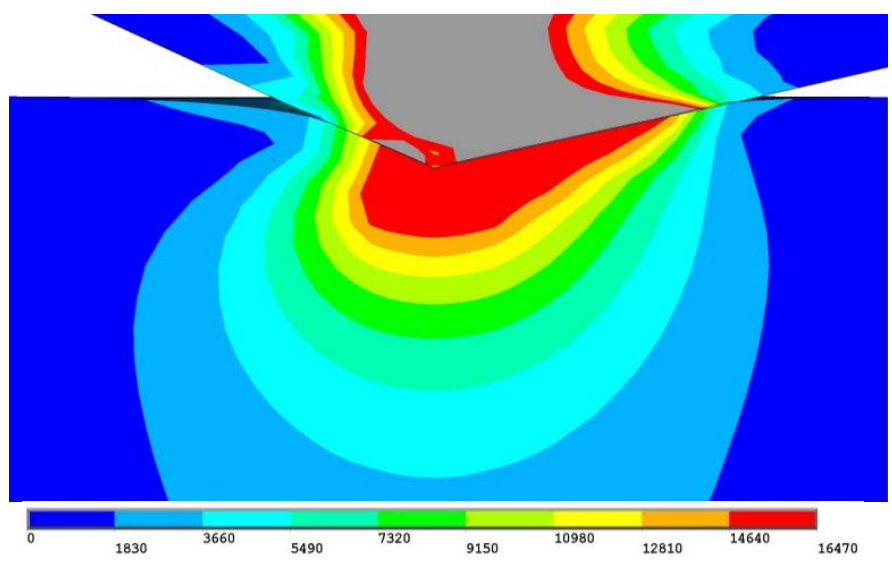

(c)

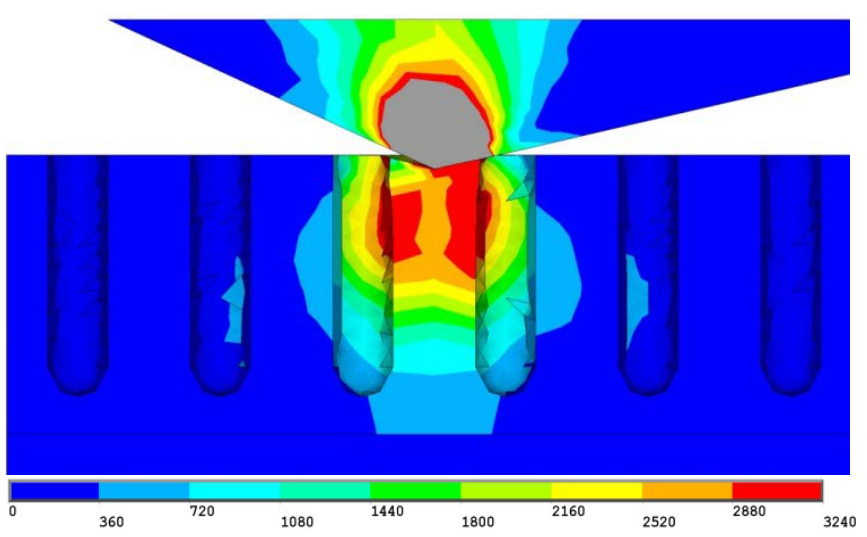

(b)

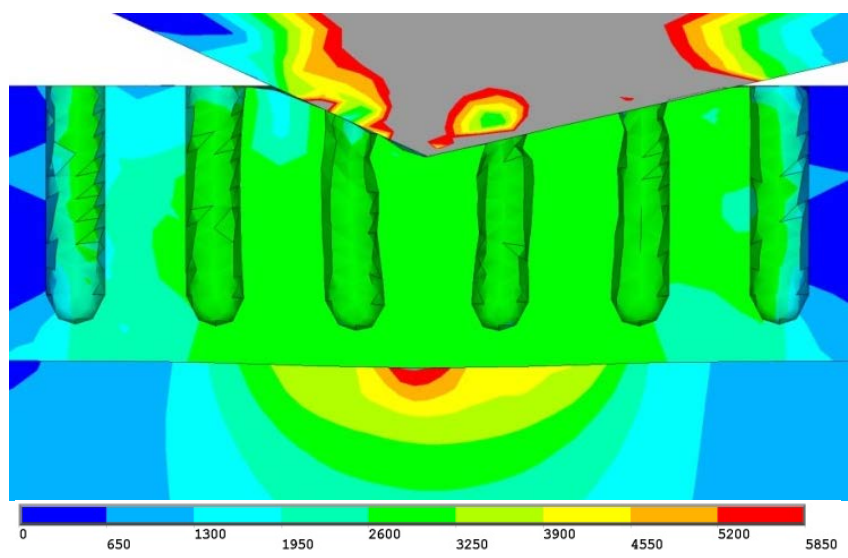

(d)

Figure 8: von Mises stress (MPa) distributions at different indentation depths: (a) $50 \mathrm{~nm}$ on glass slide, (b) $50 \mathrm{~nm}$ on AAO coating on glass substrate, (c) $250 \mathrm{~nm}$ on glass slide, and (d) $250 \mathrm{~nm}$ on AAO coating on glass substrate. 


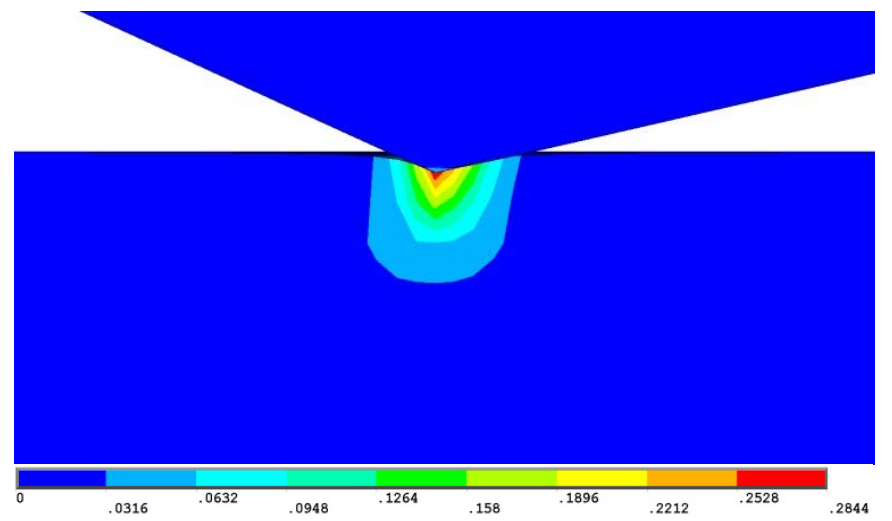

(a)

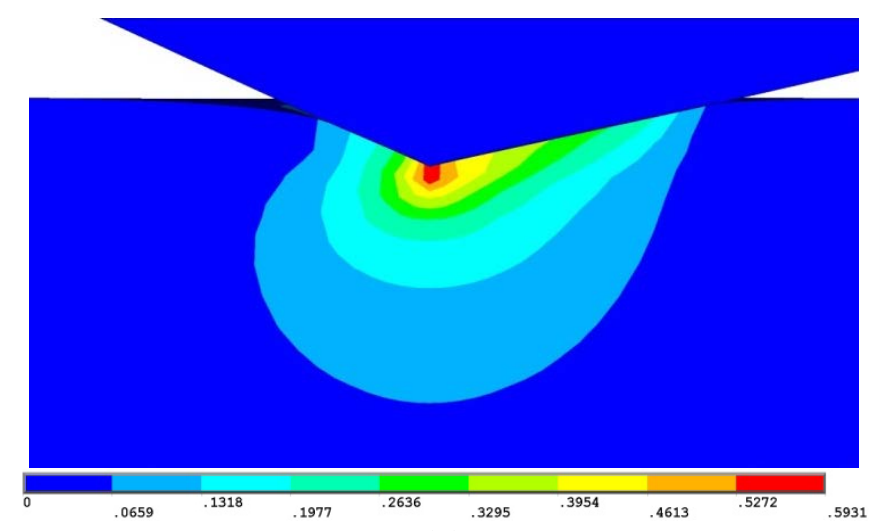

(c)

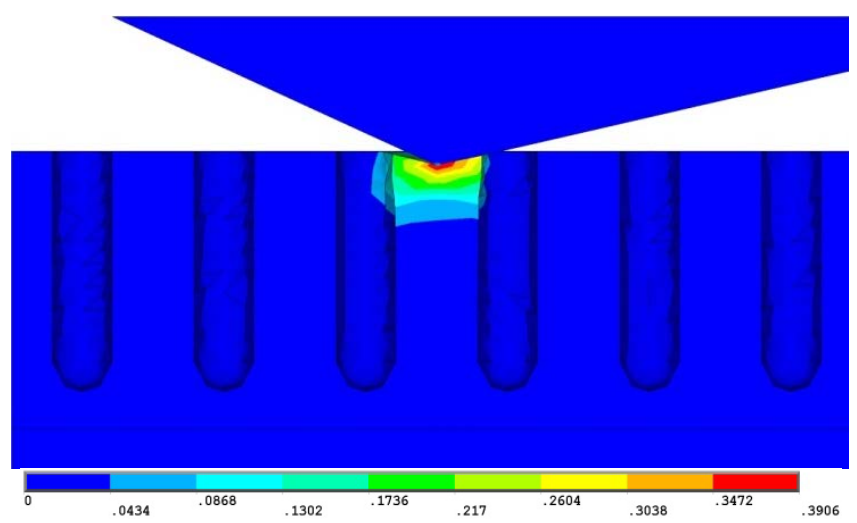

(b)

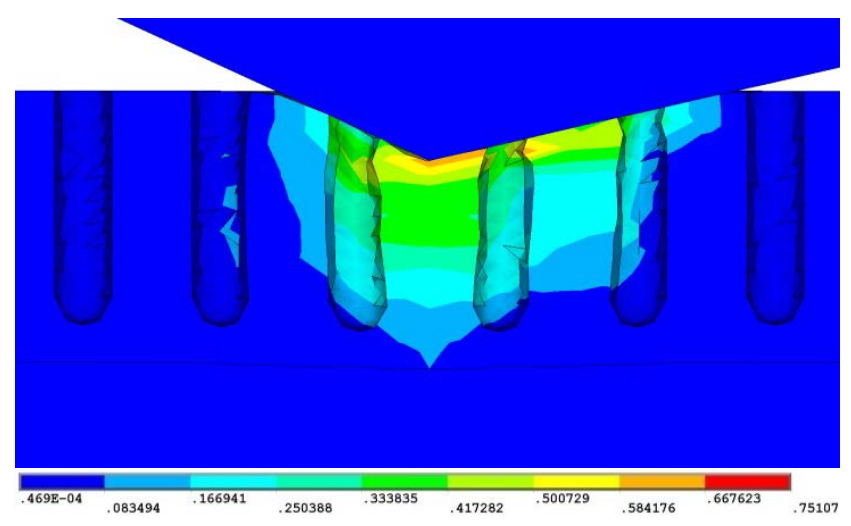

(d)

Figure 9: von Mises strain distributions at different indentation depths: (a) $50 \mathrm{~nm}$ on glass slide, (b) $50 \mathrm{~nm}$ on AAO coating on glass substrate, (c) $250 \mathrm{~nm}$ on glass slide, and (d) $250 \mathrm{~nm}$ on AAO coating on glass substrate. 